Supplement of Earth Syst. Dynam., 7, 203-210, 2016

http://www.earth-syst-dynam.net/7/203/2016/

doi:10.5194/esd-7-203-2016-supplement

(c) Author(s) 2016. CC Attribution 3.0 License.

(c) (i)

Earth System
Dynamics

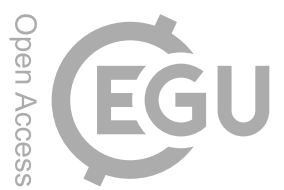

Supplement of

\title{
Delaying future sea-level rise by storing water in Antarctica
}

K. Frieler et al.

Correspondence to: A. Levermann (anders.levermann@pik-potsdam.de)

The copyright of individual parts of the supplement might differ from the CC-BY 3.0 licence. 


\section{S1 Efforts of delaying sea level rise in comparison to local adaptation}

2 Storing ocean water $700 \mathrm{~km}$ inland on the Antarctic Ice Sheet requires overcoming a height 3 difference of about $4000 \mathrm{~m}$. Mitigating a sea-level rise of $3 \mathrm{~mm}$ yr-1 requires $1275 \mathrm{GW}$ of power to increase the potential energy of the water accordingly. This corresponds to a power of $10 \mathrm{~kW}$ that is required to pump $1 \mathrm{~m}^{3} / \mathrm{s}$ vertically to a height of $1 \mathrm{~m}$. The actual energy required for the pumping will be higher due to friction and inefficient pumping. Here we assume a required power of $18 \mathrm{~kW}$ to pump $1 \mathrm{~m}^{3} / \mathrm{s}$ to a height of $1 \mathrm{~m}$. This value is based on the project Tagus-Segura Water Transfer(Melgarejo Moreno, Joaquín Sanz Montaño, 2009). In its first section (TRAMO I) a power of $135 \mathrm{MW}$ is applied to achieve a through-put of $31.7 \mathrm{~m}^{3} / \mathrm{s}$ over a height difference of $245 \mathrm{~m}$, which corresponds to 17.3 $\mathrm{kW} /\left(\mathrm{m}^{3} / \mathrm{s}\right) / \mathrm{m}$. This would mean that the required power to mitigate a sea-level rise of $3 \mathrm{~mm}$ yr-1 would reach about 2300 GW. To avoid further greenhouse-gas emissions the power would have to be generated based on local renewable technologies.

That poses a fundamental engineering problem that goes far beyond the scope of existing projects. While wind power plants and pipeline technology readily exist, currently the required technology is not available for the very low temperatures of Antarctica, as far as we know. We cannot provide reliable estimates of the associated costs at this stage.

However, to put the engineering effort into perspective we here compare the technical requirements of the pumping and transporting system to that of the Trans Alaska Pipeline (TAP)(Alyeska Pipeline Service Company, 2013). Thereby we assume that the transport of the water is split up into 90 individual pipelines each ensuring a throughput of $11 \cdot 10^{9} \mathrm{~m}^{3} \mathrm{yr}^{-1}$ as provided by the largest New Orleans pumping station. 


\begin{tabular}{|l|l|l|}
\hline & Trans Alaska Pipeline & $\begin{array}{l}\text { Individual pipeline of the } \\
\text { potential Antarctic pumping } \\
\text { system }\end{array}$ \\
\hline Length & $1287 \mathrm{~km}$ & $700 \mathrm{~km}$ \\
\hline Maximum elevation & $1444 \mathrm{~m}$ & $4000 \mathrm{~m}$ \\
\hline Air temperature along & $-60^{\circ} \mathrm{C}$ to $35^{\circ} \mathrm{C}$ & far below $0^{\circ} \mathrm{C}$ \\
\hline Annual throughput & $\begin{array}{l}0.1245 \cdot 10^{9} \mathrm{~m}^{3} \text { (assuming a } \\
\text { maximum daily throughput } \\
\text { as reached in 1988) }\end{array}$ & $11 \cdot 10^{9} \mathrm{~m}^{3}$ \\
\hline
\end{tabular}

The costs of building the TAP amount to a total of 8 billion US\$. On the one hand this includes costs not relevant for the Antarctic pipelines and pumps such as:

- costs of the Valdez oil terminal (US\$1.4)

- launching/receiving facilities for cleaning pigs that sweep the pipe of built-up wax, water or other solids that precipitate out of the oil stream

- 124,300 heat pipes along the pipeline transferring ground heat into the air during

While on the other hand the Antarctic systems will

- have to provide an orders of magnitude higher throughput (assuming 90 individual lines starting at the ocean with an annual throughput of $11.10^{9} \mathrm{~m}^{3}$ as provided by throughout the summer to steadily support the pipeline (to be replaced by alternatives adequate for Antarctica). the largest New Orleans pump station would require an upscaling of the maximum annual throughput of the TAP (calculated based on its maximum daily throughput reached in 1988) by a factor of 90 for each individual line).

- have to overcome a larger elevation difference $(4000 \mathrm{~m}$ in comparison to a maximum of $1444 \mathrm{~m}$ along the TAP)

- require heating along the pipelines 
59

$$
\approx \alpha 6.6 * 10^{12} U S \$ * 8015 * 3+(1-\alpha) 6.6 * 10^{12} U S \$ * 8015 * 50
$$

60

- require a system to distribute the water on the ice sheet

- need an adjustments of the pipeline due to moving ice

to provide a simplistic upscaling of the TAP costs excluding the terminal (6.6 US\$) to the required length $(L)$, height $(H)$, and capacity $(P)$ we assume that the overall costs $C$ can be split up in to components, a first one $\mathrm{C}_{1}$ that scales with $\mathrm{P}$ and $\mathrm{H}$ (mainly representing the costs of the pump stations) and a second one $C_{2}$ that scales with $L$ and $P$ (mainly representing the costs of the pipeline itself). Assume that the two components of the overall costs of the TAB $C_{\text {TAB }}$ are given by $C_{1, \text { TAP }}=\alpha C_{\text {TAP }}$ and accordingly $C_{2, \text { TAP }}=(1-\alpha) C_{\text {TAP }}$ that would mean that

$$
\mathrm{C}=C_{1, T A B} * \frac{P}{P_{T A B}} * \frac{H}{H_{T A B}}+C_{2, T A B} * \frac{P}{P_{T A B}} * \frac{L}{L_{T A B}}
$$

with $C=158,697$ billion US\$ for $\alpha=1$ and $C=2,644,950$ billion US\$ for $\alpha=0$. Both numbers do not include the costs of running and maintaining the system. Assuming they are minor compared to the cost of construction, construction costs could be divided by 100 to estimate the annual costs over the $21^{\text {st }}$ century. In both cases they are orders of magnitude higher than the estimated annual investment and maintenance costs of local adaptation by dikes of US\$ $12-71$ billion in 2100(Hinkel et al., 2014) which however only protects regions that are economically expendient to protect. This might exclude for example the AOSIS small island states and their culture as well as UNESCO cultural heritage sites(Marzeion and Levermann, 2014).

That means that such a project would only become competitive with major efficiency gains by technical innovations and learning from the experience of the project itself. 


\section{S2 Wind Energy potential in Antarctica}

77 We follow the methodology of ref. (Archer and Jacobson, 2005) to estimate the wind energy that is available in a $200 \mathrm{~km}$ wide band along the East Antarctic coast (Fig. S1). We use the yearly mean wind data for 2014 at $10 \mathrm{~m}$ above the surface from the Era-Interim dataset(ECMWF, n.d.). Following ref. (Archer and Jacobson, 2005), we use only regions with average wind speed above $6.5 \mathrm{~m} / \mathrm{s}$. The power of a single wind turbine can be estimated by (ref. (Archer and Jacobson, 2005), equ. 19):

83

with $\mathrm{P}$ as average power output, $\mathrm{P}_{\text {rated }}$ the rated power of a single wind turbine, $\mathrm{CF}$ the conversion factor, $V$ the average yearly wind speed and $D$ the rotor diameter of the wind turbine. Six wind turbines of the $1.5 \mathrm{MW}$ class can be installed per square kilometre(Archer and Jacobson, 2005). Integrating over the East Antarctic band area with wind stronger than $6.5 \mathrm{~m} / \mathrm{s}$, we estimate a wind power potential of 16.7 TW. Regions difficult to access, such as mountain ranges, and regions of fast flowing ice have not been excluded from the total area. We do not apply a conversion of $10 \mathrm{~m}$ above-surface winds to such at the height of the rotor (80m in ref. (Archer and Jacobson, 2005)). As winds at $80 \mathrm{~m}$ are generally higher than at $10 \mathrm{~m}$ above the surface, the real wind energy potential may be higher.

Wind power utilization in Antarctica will pose a number of major challenges that cannot be addressed here. These include building fundaments on moving and deformable ground, functioning under extremely cold temperatures in Antarctic winters and handling very high wind velocities. 


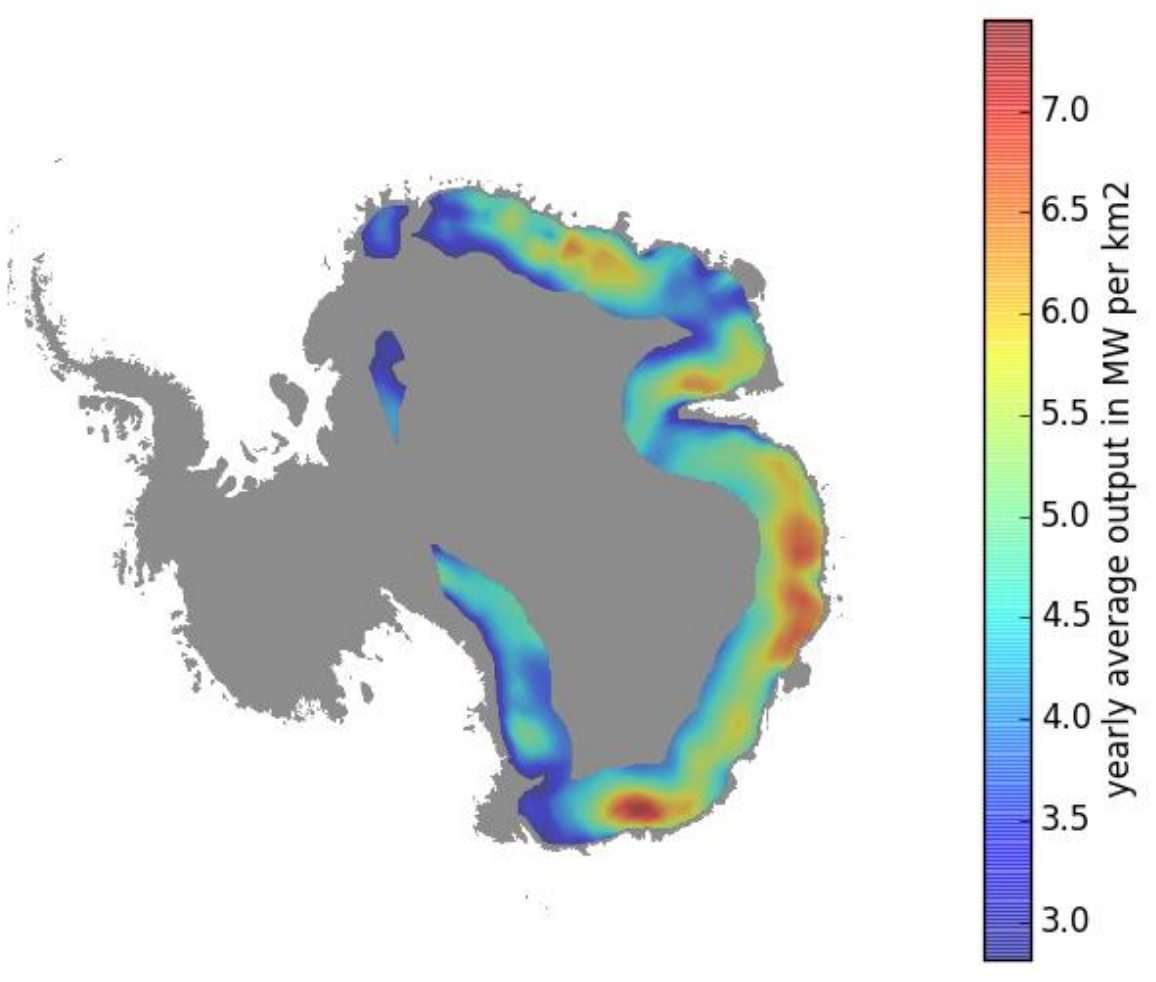

99

100 Fig. S1: Wind energy potential in East Antarctica. Using ERA-Interim data(ECMWF, n.d.), we

101 use the methodology of ref. (Archer and Jacobson, 2005) to estimate the wind power

102 potential in a $200 \mathrm{~km}$-wide strip along the East Antarctic coast. High wind speeds above 6.5

$103 \mathrm{~m} / \mathrm{s}$ on yearly average in the major part of the strip allow for large-scale wind energy

104 extraction.

105

106

107

108

109 


\section{S3 Modelled initial equilibrium ice sheet state}

observed surface elevation and grounding line

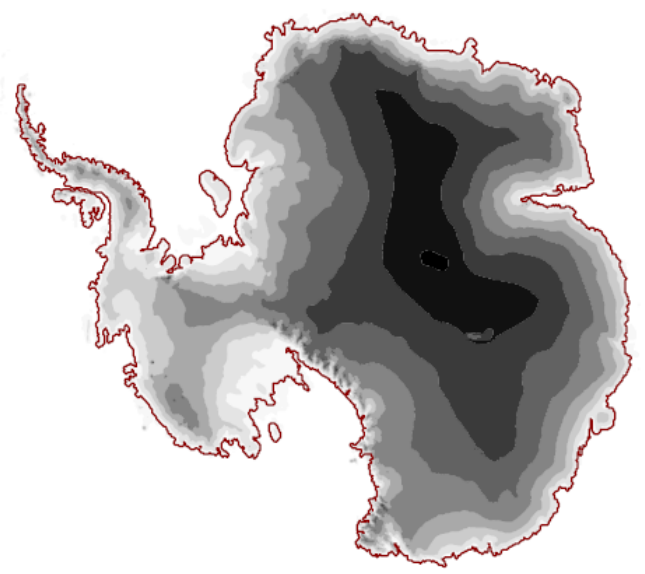

simulated surface elevation

and grounding line

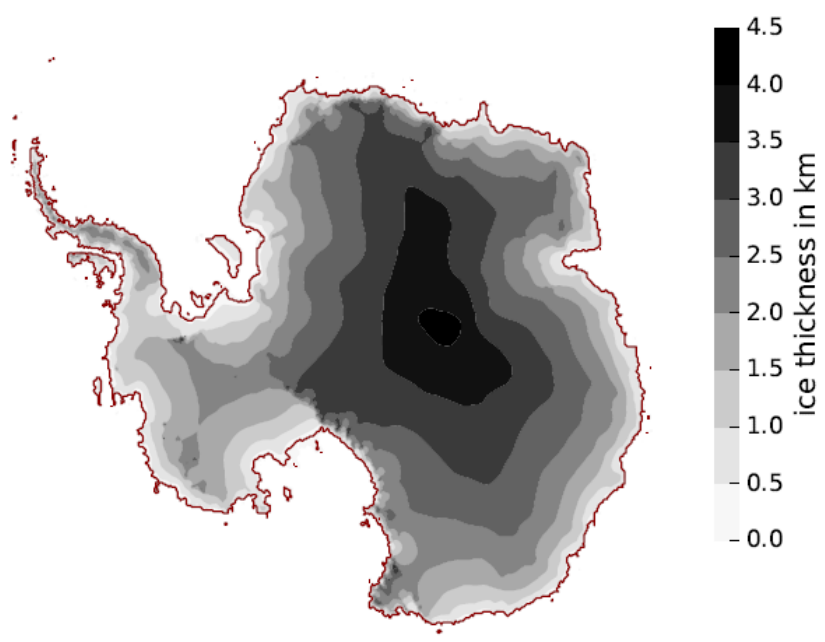

114 Fig. S2: Comparison of the currently observed surface elevation and grounding line

115 position (left panel) to the simulated initial state of the ice sheet (right panel). The

116 grounding line (red line, Bindschadler et al., 2011) is generally well reproduced for East

117 Antarctica and most parts of West Antarctica. East Antarctica's modelled surface elevation

118 compares well to the observed state (Fretwell et al., 2013). The modelled surface elevation

119 is slightly higher close to the South pole and slightly lower towards the East Antarctic coast

120 as compared the observation. 
observed velocities

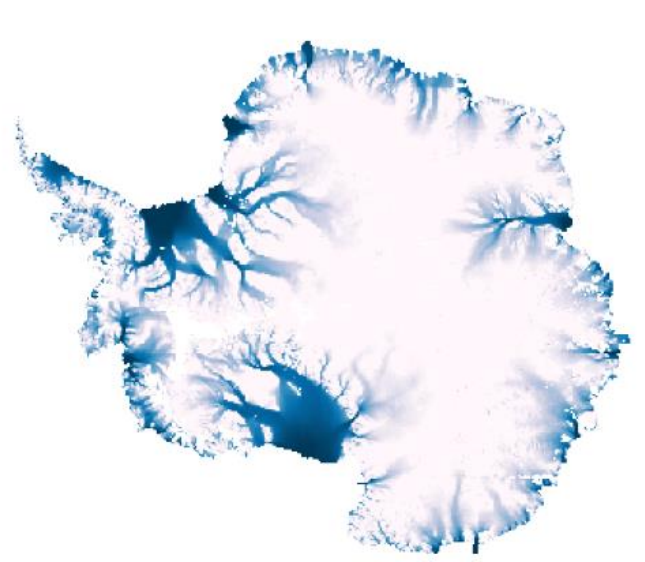

simulated velocities

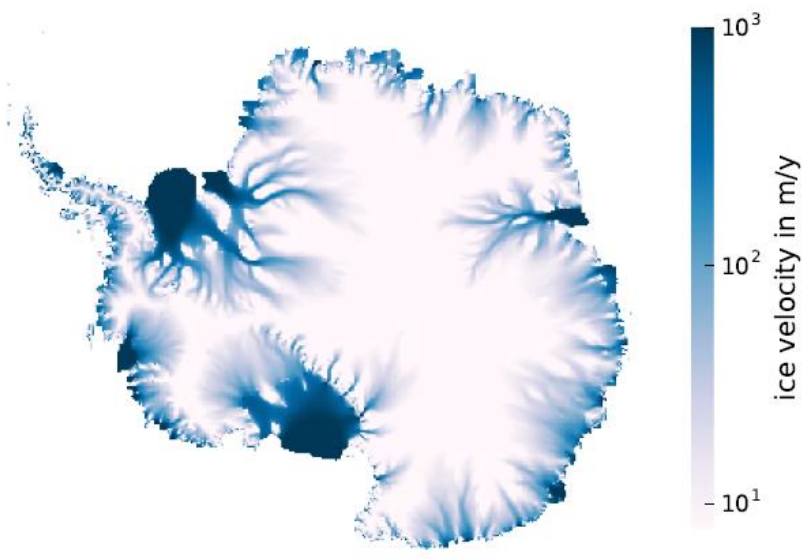

126 Fig. S4: Comparison of the currently observed ice velocities at the surface (left panel,

127 Rignot et al., 2011) to the velocities of the simulated initial state of the ice sheet (right

128 panel). The model reproduces the flow features of the East Antarctic ice sheet.

129

130

131

132 


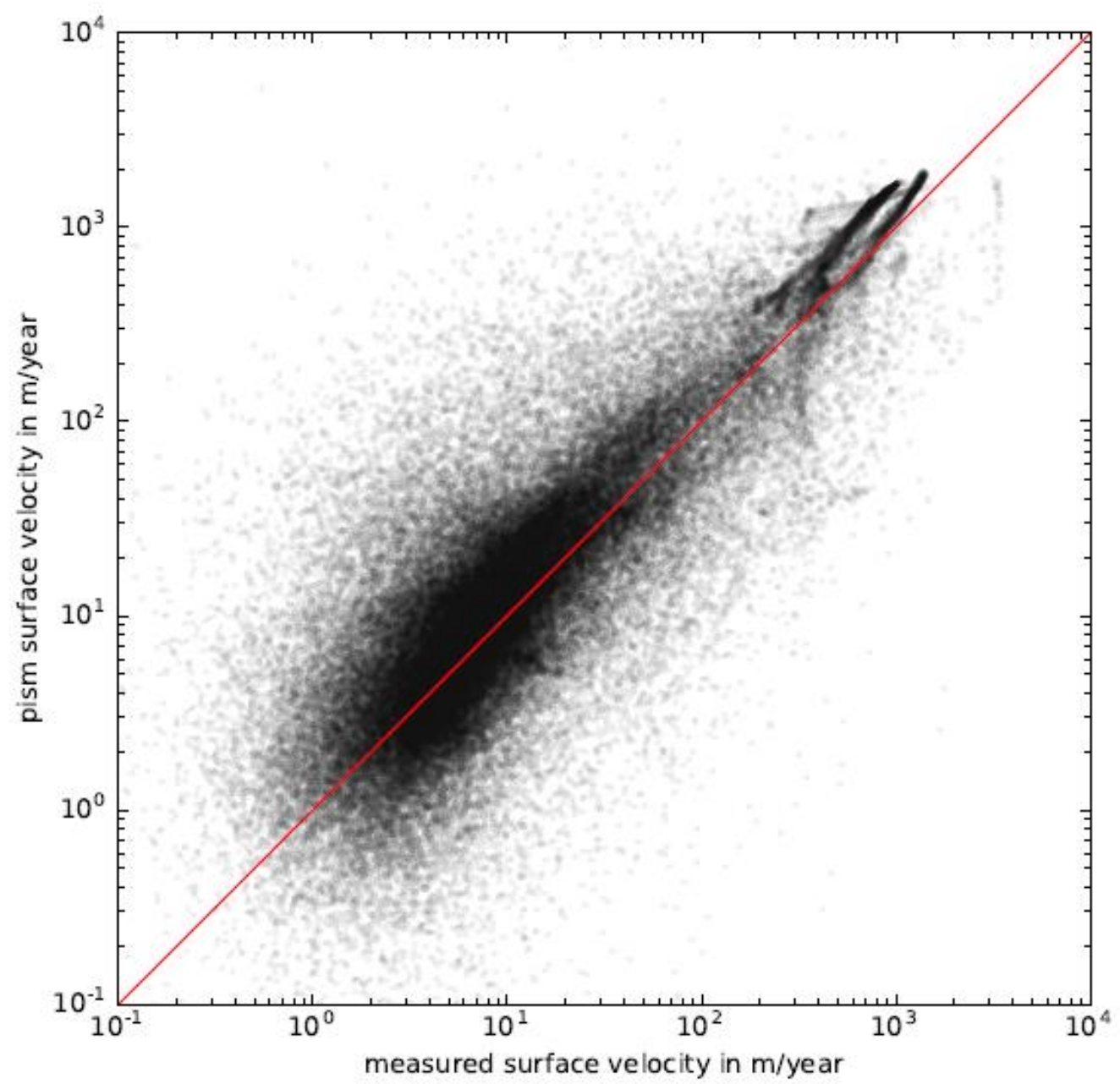

133

134 Fig. S5: Observed and modelled velocities, point-to-point comparison on log-log scale.

135 Observed velocities (Rignot et al., 2011) are on the $x$-axis and modelled velocities on the $y$ 136 axis. 


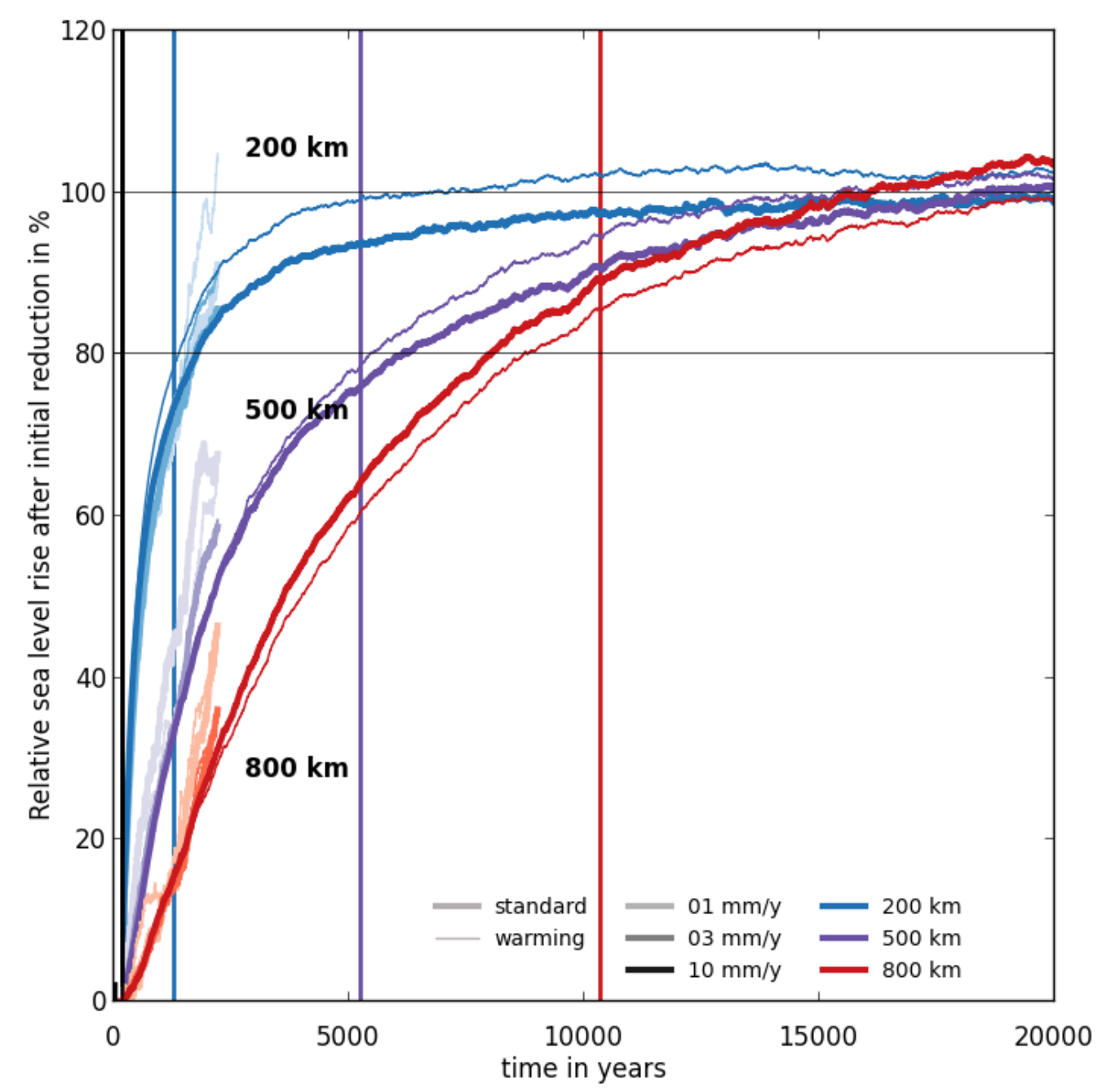

140 Fig. S5: Delayed sea-level rise as fraction of the initial reduction. Colour coding indicates

141 the application band where the ice is added (red: $800 \mathrm{~km}$ distance from the coast, violet:

$142500 \mathrm{~km}$ distance from the coast, and blue: $200 \mathrm{~km}$ distance from the coast). The colour

143 intensity describes the application rate from $1 \mathrm{~mm} \mathrm{yr}^{-1}$ (light), via $3 \mathrm{~mm} \mathrm{yr}^{-1}$ (normal) to 10

$144 \mathrm{~mm} \mathrm{yr}^{-1}$ (dark). Thin lines show the results of the simulations accounting for latent-heat 145 release while thick lines represent the results without the additional warming. Vertical lines 146 mark the $5^{\text {th }}$ percentile of the distribution of delay times assuming an ice parcel traveling $147800 \mathrm{~km}$ (red), $500 \mathrm{~km}$ (violet), and $200 \mathrm{~km}$ (blue) with a constant surface velocity drawn 148 from the distribution of surface velocities observed within the area of less than $800 \mathrm{~km}, 500$ 
149

150

151

152

153

154

155

156

157

158

159

160

161

162

163

164

165

166

167

168

169

170

171

172

173

174

175

176

177

178

179

180

181

$\mathrm{km}$ and $200 \mathrm{~km}$ distance from the coast. Real advection of ice particles to the coast by the surface velocities will even take longer because generally the ice will not be flowing the direct path assumed here.

\section{References}

Alyeska Pipeline Service Company: FACTS, Trans Alaska Pipeline System, Anchorage, Alaska. [online] Available from: www.alyeska-pipe.com, 2013.

Archer, C. L. and Jacobson, M. Z.: Evaluation of global wind power, J. Geophys. Res., 110(D12), 1-20, doi:10.1029/2004JD005462, 2005.

Bindschadler, R., Choi, H. and ASAID Collaborators: High-resolution Image-derived Grounding and Hydrostatic Lines for the Antarctic Ice Sheet, Boulder, Colorado, USA. [online] Available from: http://dx.doi.org/10.7265/N56TOJK2, 2011.

ECMWF: ERA-Interim, 2015 [online] Available from: http://apps.ecmwf.int/datasets/data/interim-full-daily/, n.d.

Fretwell, P., Pritchard, H. D., Vaughan, D. G., Bamber, J. L., Barrand, N. E., Bell, R., Bianchi, C., Bingham, R. G., Blankenship, D. D., Casassa, G., Catania, G., Callens, D., Conway, H., Cook, A. J., Corr, H. F. J., Damaske, D., Damm, V., Ferraccioli, F., Forsberg, R., Fujita, S., Gim, Y., Gogineni, P., Griggs, J. A., Hindmarsh, R. C. A., Holmlund, P., Holt, J. W., Jacobel, R. W., Jenkins, A., Jokat, W., Jordan, T., King, E. C., Kohler, J., Krabill, W., Riger-Kusk, M., Langley, K. A., Leitchenkov, G., Leuschen, C., Luyendyk, B. P., Matsuoka, K., Mouginot, J., Nitsche, F. O., Nogi, Y., Nost, O. A., Popov, S. V., Rignot, E., Rippin, D. M., Rivera, A., Roberts, J., Ross, N., Siegert, M. J., Smith, A. M., Steinhage, D., Studinger, M., Sun, B., Tinto, B. K., Welch, B. C., Wilson, D., Young, D. A., Xiangbin, C. and Zirizzotti, A.: Bedmap2: improved ice bed, surface and thickness datasets for Antarctica, Cryosph., 7, 375-393, doi:doi:10.5194/tc-7-375-2013, 2013.

Hinkel, J., Lincke, D., Vafeidis, A. T., Perrette, M., Nicholls, R. J., Tol, R. S. J., Marzeion, B., Fettweis, X., lonescu, C. and Levermann, A.: Coastal flood damages and adaptation costs under 21st century sea-level rise, PNAS, 111(9), 3292-3297, 2014.

Marzeion, B. and Levermann, A.: Loss of cultural world heritage and currently inhabited places to sea-level rise, Environ. Res. Lett., 9(3), 034001, doi:10.1088/17489326/9/3/034001, 2014.

Melgarejo Moreno, Joaquín Sanz Montaño, B.: La eficiencia energética del trasvase TajoSegura, in Cuaderno Interdisciplinar de Desarrollo Sostenible, p. 174., 2009. 
182 Rignot, E., Mouginot, J. and Scheuchl, B.: Ice flow of the Antarctic ice sheet." Science 183333.6048 (2011): 1427-1430., Science (80-. )., 333(6048), 1427-1430, 2011. 